\title{
A doença periodontal como um fator de risco para o câncer de pâncreas
}

Periodontal disease as a risk factor for cancer

Enfermedad periodontal como factor de riesgo de cáncer

Carla Graciele SANTOS ${ }^{1}$

João Marcos da Costa LUCENA ${ }^{1}$

Ocimar Lopes de OLIVEIRA ${ }^{\mathbf{1}}$

Júlia Kiara da Nóbrega HOLANDA ${ }^{1}$

Raline Mendonça dos ANJOS ${ }^{1}$

Aleson Pereira de SOUSA ${ }^{2}$

Abrahão Alves de OLIVEIRA FILHO ${ }^{3}$

${ }^{1}$ Universidade Federal de Campina Grande UFCG 58428-830 Campina Grande - PB, Brasil

${ }^{2}$ Programa de Pós-Graduação em Desenvolvimento e Inovação Tecnológica em Medicamentos, Universidade Federal da Paraíba (DITM/UFPB) 58051-970 - João Pessoa - PB, Brasil

${ }^{3}$ Professor Doutor, Unidade Acadêmica de Ciências Biológicas, Centro de Saúde e Tecnologia Rural, Universidade Federal de Campina Grande UFCG 58428-830 Campina Grande - PB, Brasil

\section{Resumo}

A neoplasia pancreática ganhou destaque por sua alta letalidade e perspectiva de aumento da incidência no mundo, sendo a doença periodontal apontada como um dos fatores de risco para o desenvolvimento dessa patologia. Os patógenos encontrados na doença periodontal, como a Porphyromonas gingivalis e a Helicobacter pylori desencadeiam uma resposta inflamatória no hospedeiro que podem promover a carcinogênese pancreática. A resposta condicionada pelos agentes microbianos da doença periodontal, resulta no aumento de marcadores inflamatórios que estão expressos no câncer de pâncreas. De tal modo, esta pesquisa teve como intuito realizar uma revisão de literatura narrativa de estudos que correlacionam o câncer de pâncreas com a Doença Periodontal, tendo as plataformas Google Acadêmico e Scielo (Scientific Eletronic Library Online) como fonte de pesquisa, utilizando os seguintes descritores: "Câncer", "Câncer de pâncreas" e "Doença periodontal", durante os meses de Maio e Julho do ano de 2020. Os artigos selecionados foram do ano de 2003 ao ano de 2019. A realização de mais pesquisas sobre essa correlação se faz necessária, para que haja esclarecimento sobre a ligação entre essas doenças.

Descritores: Neoplasias; Neoplasias Pancreáticas; Doenças Periodontais.

\section{Abstract}

Pancreatic neoplasia gained prominence due to its high lethality and perspective of increased incidence in the world, with periodontal disease being identified as one of the risk factors for the development of this pathology. Pathogens found in periodontal disease, such as Porphyromonas gingivalis and Helicobacter pylori trigger an inflammatory response in the host that can promote pancreatic carcinogenesis. The response conditioned by microbial agents of periodontal disease results in an increase in inflammatory markers that are expressed in pancreatic cancer. In this way, this research aimed to conduct a narrative literature review of studies that correlate pancreatic cancer with Periodontal Disease, using the Google Scholar and Scielo (Scientific Electronic Library Online) platforms as a research source, using the following descriptors : "Cancer", "Pancreatic cancer" and "Periodontal disease", during the months of May and July of the year 2020. The selected articles were from 2003 to 2019. Further research on this correlation is carried out makes it necessary, so that there is clarification about the connection between these diseases.

Descriptors: Neoplasms; Pancreatic Neoplasms; Periodontal Diseases.

\section{Resumen}

La neoplasia de páncreas ganó protagonismo por su alta letalidad y perspectiva de mayor incidencia en el mundo, identificándose la enfermedad periodontal como uno de los factores de riesgo para el desarrollo de esta patología. Los patógenos que se encuentran en la enfermedad periodontal, como Porphyromonas gingivalis y Helicobacter pylori, desencadenan una respuesta inflamatoria en el huésped que puede promover la carcinogénesis pancreática. La respuesta condicionada por agentes microbianos de la enfermedad periodontal da como resultado un aumento de los marcadores inflamatorios que se expresan en el cáncer de páncreas. De esta manera, esta investigación tuvo como objetivo realizar una revisión de la literatura narrativa de los estudios que correlacionan el cáncer de páncreas con la Enfermedad Periodontal, utilizando las plataformas Google Scholar y Scielo (Scientific Electronic Library Online) como fuente de investigación, utilizando los siguientes descriptores : "Cáncer", "Cáncer de páncreas" y "Enfermedad periodontal", durante los meses de mayo y julio del año 2020. Los artículos seleccionados fueron de 2003 a 2019. Se realizan más investigaciones sobre esta correlación lo hace necesario, para que se aclare la conexión entre estas enfermidades.

Descriptores: Neoplasias; Neoplasias Pancreáticas; Enfermedades Periodontales.

INTRODUÇÃO

O câncer, também denominado de

neoplasia, consiste na proliferação descontrolada de células transformadas. Essa alteração pode ocorrer em proto-oncogenes, genes especiais que são quiescentes em células normais, e que com sua ativação passam a ser chamados de oncogenes, causando mutação celular, e sendo nomeadas de células cancerosas ou tumorais ${ }^{1}$.

Células tumorais são geralmente menos especializadas que células saudáveis. Dessa maneira, conforme as células malignas vão se proliferando e substituindo as saudáveis, os tecidos invadidos vão perdendo sua função, podendo culminar em falência do órgão e consequentemente, do paciente ${ }^{1}$.

A neoplasia de pâncreas é a uma das causas mais fatais de câncer nos Estados Unidos $^{2}$. Neste, chega a ser o quarto tipo de morte por câncer e com perspectiva de se tornar em 2030, o segundo de maior incidência ${ }^{3}$.

Já no Brasil, corresponde a $2 \%$ dos tipos de neoplasias e $4 \%$ das causas de morte por esse tipo de doença. Apesar do câncer de pâncreas não estar entre os principais tipos de neoplasias no Brasil, ele caracteriza a oitava 
causa de morte por câncer, visto que os pacientes diagnosticados são em sua maioria em fase progressiva ${ }^{3}$.

O adenocarcinoma ductal do pâncreas (ADP) é o tipo de câncer de pâncreas mais comum, ele tem origem no pâncreas exócrino e é responsável por $95 \%$ dos casos, que em sua maioria são do sexo masculino. A taxa de sobrevida de pacientes com ADP é de $5 \%$ em cinco anos, caracterizando-se com uma alta taxa de letalidade. Além disso, conforme o aumento da idade, sua incidência aumenta ${ }^{3}$.

Entre os fatores de risco para o câncer de pâncreas, destacam-se: o consumo de álcool, obesidade, sedentarismo, diabetes, pancreatite crônica e doença periodontal ${ }^{4}$.

A doença periodontal (DP) é a segunda patologia dentária mais comum no mundo, sendo causada pela resposta inflamatória do hospedeiro à bactéria e seus produtos ${ }^{5}$.

A placa dentária se acumula ao longo da margem gengival, tal placa contém bactérias que estimulam uma resposta inflamatória. $O$ primeiro sinal clínico da patologia é a gengivite, seguida de periodontite caso haja a progressão da doença. Há também perda de inserção dos tecidos periodontais, e em casos mais graves, a perda dentária ${ }^{6}$.

Os principais aspectos clínicos da periodontite são: gengiva edemaciada, com hiperplasia, hemorragia durante a escovação ou ao toque, perda do tecido ósseo de suporte, presença de cálculo supra e subgengival, bem como recessão gengival ${ }^{7}$.

Entre os fatores de riscos para 0 desenvolvimento da DP, os principais são: a falta de higiene oral, baixo nível socioeconômico e alterações no foro sistêmico, como é o caso da diabetes, e do uso de medicamentos ${ }^{7}$.

Além disso, para o desenvolvimento da DP é necessário que haja a colonização de bactérias na superfície dentária (biofilme ou placa bacteriana). As bactérias que demonstram relevância para o desenvolvimento da periodontite são: Actinobacillus actinomycetemcomitans, Porphyromonas gengivalis e Tanerella forsythensis ${ }^{8}$. O Propósito deste trabalho foi revisar na literatura os estudos que correlacionam o câncer de pâncreas com a doença periodontal.

MATERIAL E MÉTODO

A pesquisa se trata de uma revisão narrativa de literatura, a qual consiste em uma temática mais aberta, apresentando-se dificilmente como com uma questão especifica e sem protocolo rígido para sua realização ${ }^{9}$. A pesquisa foi feita na plataforma do Google
Acadêmico e Scielo (Scientific Eletronic Library Online), utilizando os seguintes descritores: "Câncer", "Câncer de pâncreas" e "Doença periodontal", durante os meses de Maio e Julho do ano de 2020. Os artigos selecionados foram do ano de 2003 ao ano de 2019.

RESULTADOS E DISCUSSÃO

- O pâncreas e suas funções

O pâncreas é dividido em duas porções: endócrina e exócrina. A primeira está envolvida na regulação do metabolismo corporal e celular. A segunda por sua vez, está envolvida no processo de digestão ${ }^{10}$.

A porção endócrina do pâncreas por meio das ilhotas de Langerhans (composta por células $\alpha, \beta, \delta$ e PP) controla os níveis de glicose presente na corrente sanguínea, secretando hormônios como glucagon, insulina e amilina, somatostatina e polipeptídeo pancreático, os quais mantém normais os níveis glicêmicos após as refeições ou durante um jejum ${ }^{11}$.

Já a porção exócrina pancreática secreta $\mathrm{NaCl}$ e enzimas digestivas, como: enzimas ativas ( $\alpha$-amilase, lipase, colipase, lipase de éster carboxílico, RNAse, DNAse), e zimogênios (tripsina, quimotripsinogênio, procarboxipeptidases $A$ e $B$, proelastase $e$ proprotease E). Essas secreções formam 0 suco pancreático, o qual contribui para a quebra de macromoléculas durante a digestão e ajuda na neutralização do quimo ácido que chega ao duodeno ${ }^{10}$.

- Fisiopatologia do câncer de pâncreas

Os genes que estão envolvidos na patogênese da carcinogênese pancreática são divididos em três categorias: genes supressores de tumores, oncogenes e genes de reparo de incompatibilidade de DNA ${ }^{12}$.

O oncogene mais comumente ativado é K-ras, sendo característica de $90 \%$ dos ADPs. Os genes supressores tumorais de maior frequência mutacional são: p16 (27\%-98\%), p53 $(40 \%-75 \%)$ e MADH4 $(55 \%)^{13}$.

O gene supressor de tumor p16 é inativado em $95 \%$ dos casos, ocorrendo tipicamente após o câncer de pâncreas. Já o gene supressor TP53 é o segundo de maior frequência, que é bem caracterizado, de inativação tardia e localizado no cromossomo 17p. Ainda, o gene MADH4 é inativado em 55\% dos ADPs e também possui uma inativação $\operatorname{tardia}^{14}$.

Acredita-se que o câncer de pâncreas esteja relacionado a uma mutação em oncogenes e genes supressores de tumores, bem como com a anormalidade de fatores de 
crescimento e seus supressores, que estão relacionados as vias de transdução de sinais envolvidas na proliferação e crescimento celular $^{14}$. Quando ocorre mutação no gene Kras, há a produção de uma proteína Ras atípica, a qual é bloqueada em sua forma ativada, resultando na ativação exacerbada das vias de sinalização relacionadas a proliferação e crescimento celular ${ }^{15}$.

Estudos em camundongos mostraram que para o desenvolvimento da neoplasia intraepitelial pancreática, precursora de câncer de pâncreas, há uma série de mutações que incluem a ativação do oncogene K-ras, inativação do gene supressor de tumor CDKN2A e inativação do gene supressor de tumor TP53 ${ }^{15}$.

A inflamação causada por lipopolissacarídeos (LPS) parece super estimular o gene K-ras mutado. Essa inflamação age como potencializadora da proliferação celular, de angiogênese, inibidora de apoptose e da adaptação ao estresse oxidativo ${ }^{11}$.

Alguns mediadores inflamatórios, citoquinas e espécies reativas de oxigênio (EROS) produzem uma alteração na expressão de genes envolvidos no câncer pancreático, podendo levar a um dano no gene e na proliferação celular. Como resultado, ocorrem lesões neoplásicas no pâncreas e posteriormente $\mathrm{ADP}^{16}$.

Ainda, estudos mostraram que a neoplasia pancreática contém superexpressão de fatores de crescimento e seus receptores, como o fator de crescimento de fibroblastos, e a transformação de Interleucina-1, Interleucina-6 e fator de necrose tumoral $\alpha$. Assim, o aumento desses fatores de crescimento e a perturbação de fatores que inibem o crescimento levam a independência na proliferação celular, angiogênese e metástase ${ }^{14}$.

\section{- Fisiopatologia da doença periodontal}

A DP consiste em uma doença inflamatória crônica, a qual em seu estado avançado desencadeia na perda de inserção do ligamento periodontal e do osso alveolar. Além disso, é considerada a doença oral mais comum no mundo e com maior risco de perda dentária ${ }^{17}$.

O acúmulo de biofilme bacteriano que se forma nos dentes leva a uma inflamação na gengiva, condição denominada de gengivite. Caso essa condição não seja tratada, pode levar a criação de bolsas periodontais e consequentemente perda de ligamento periodontal e osso alveolar. Em casos mais avançados da doença, a DP resulta em perda dentária $^{18}$.
Ao contato com a microbiota que causa a DP, o hospedeiro inicia sua resposta de defesa, que pode ser: específica, quando o hospedeiro já teve contato com os agentes bacterianos, ou inespecífica, caso nunca tenha ocorrido um contato prévio com essa microbiota. Dessa maneira, a resposta de defesa condiciona se haverá ou não lesões celulares e teciduais ${ }^{5}$. Assim, a intensidade da resposta inflamatória do hospedeiro condiciona muito mais a periodontite do que a quantidade de microbiota que está disponível na cavidade oral $^{19}$.

Ao contato com os agentes bacterianos específicos, há um desequilíbrio entre a microbiota e a defesa do hospedeiro, levando a modificações celulares e a inflamação. Esta fase se caracteriza como gengivite ${ }^{5}$.

A gengivite é representada por uma inflamação na gengiva, causada por bactérias do biofilme dental, sendo percebida devido a vermelhidão e edema na região gengival. Diferente da periodontite, a gengivite induzida por placa é reversível quando tratada ${ }^{20}$.

A gengivite não tratada progride para periodontite, levando a perda dos tecidos periodontais, e a formação de bolsas periodontais, que pode resultar na perda dos dentes ${ }^{18}$.

As bactérias específicas que causam DP, devido sua toxicidade, estimulam algumas células, como os neutrófilos, fibroblastos, células epiteliais e monócitos. A estimulação dessas células acarreta uma série de alterações. Os fibroblastos quando estimulados libertam as metaloproteinases (MPM), estas por sua vez, destroem o colágeno. As demais células liberam as prostaglandinas, principalmente a PGE2, que libertam algumas citoquinas como: Interleucina 1, Interleucina 6 e fator de necrose tumoral, as quais estimulam a liberação de osteoclastos e consequentemente a reabsorção óssea ${ }^{5}$.

As bactérias causadoras da DP são as mesmas da placa dental. Portanto, é importante uma boa higiene oral, afim de evitar a formação de placa bacteriana e consequentemente da $\mathrm{DP}^{21}$.

Além disso, com a presença biofilme há dificuldade na penetração do antibiótico nessa área, uma vez que o biofilme contém polímeros extracelulares, que funcionam como uma cola, a qual une as bactérias ${ }^{19}$.

\section{- Doença Periodontal e Câncer de Pâncreas}

A cavidade oral é fonte de bactérias compostas por mais de setecentas espécies, sendo a saliva um biomarcador viável para doenças não orais. Assim, as bactérias que 
estão presentes na cavidade oral podem difundir-se através do tecido gengival até o pâncreas, por intermédio do trato gastrointestinal| ${ }^{22}$.

As bactérias causadoras da DP, seus componentes, como endotoxina, e seus subprodutos metabólicos podem causar toxicidade nas células circundantes e desencadear mutações em proto-oncogenes e genes supressores de tumores, por consequência alterar vias de sinalizações envolvidas no mecanismo de proliferação celular $^{23}$.

\section{- Porphyromonas gingivalis}

A $P$. gingivalis é uma bactéria que coloniza a cavidade oral, sendo encontrada principalmente na placa supragengival. Ela pertence ao grupo Porphyromonas e a família Bactereoidaceae, sendo um coco-bacilo gramnegativo e anaeróbico estrito ${ }^{8}$.

A $P$. gingivalis é um importante fator etiológico para o desenvolvimento da DP, em que para o mecanismo de adesão a cavidade oral, essa bactéria utiliza de várias estruturas, fatores de virulência, que contribuem para 0 desencadeamento da patologia, tais como: fímbrias, proteases, hemaglutininas e LPS ${ }^{8}$.

No estudo realizado por Ahn et al. ${ }^{24}$, em que seu objetivo era verificar a correlação da bactéria $P$. gingivalis com a mortalidade por câncer digestivo, abrangendo o câncer de pâncreas, foram coletadas amostras de um soro que continha anticorpos para a $P$. gingivalis. De doze mil, seiscentos e cinco indivíduos como amostra, mil oitocentos e vinte e seis $(14,48 \%)$ tinham periodontite moderada e trezentos e setenta e nove (3\%) tinham periodontite severa. Nesse estudo, o câncer de pâncreas tendeu a ser relacionado a periodontite, sendo o risco de mortalidade aumentado de acordo com a gravidade da DP.

Ademais, no estudo de Michaud et al. ${ }^{25}$ foram medidos anticorpos para bactérias orais em quatrocentos e cinco casos prediagnosticados de carcinogênese pancreática e quatrocentos e dezesseis casos controles correspondentes, chegando a conclusão de que indivíduos que possuíam anticorpos para a $P$. gingivalis ATTC 53978, tinham duas vezes mais chances de desenvolver o câncer de pâncreas do que os indivíduos com níveis mais baixos desse anticorpo.

No estudo de Zambirinis e Miller ${ }^{26}$, os receptores toll-like demonstraram desempenhar um papel significante no câncer de pâncreas. Nessa patologia, os receptores TLR4 e TLR7 estão super expressos. Em camundongos, quando ativado junto a ligantes exógenos, 0
TLR aumentava a inflamação pancreática em pancreatite e acelerava 0 processo de carcinogênese. Já o bloqueio desse receptor, retardava a progressão do tumor.

A bactéria $P$. gingivalis induz a inflamação, bem como o LPS dessa bactéria desencadeia uma resposta imune por receptores TLR2 E TLR4. Os receptores TLR4 além de induzirem a apoptose, promovem crescimento e angiogênese do tumor. A sinalização do TLR apresenta-se como um vínculo entre a estimulação microbiana e a neoplasia pancreática ${ }^{27}$.

$\mathrm{Na}$ inibição da apoptose de células epiteliais por $P$. gingivalis, o gene supressor de tumor p53 pode ser ativado ${ }^{28}$.

Há altas taxas de mutações no gene supressor de tumor p53 e no oncogene K-ras nas mutações argininas, indicando fator prognóstico de ADP. A $P$. gingivalis secreta a enzima peptidil-arginina-desiminase, a qual degrada a arginina, com possibilidade de resultar em mutação no gene p53 e oncogene K-ras ${ }^{29}$.

- Helicobacter pylori

A Helicobacter pylori é uma bactéria pertencente ao gênero Helicobacter, que contém mais de vinte e sete espécies adaptadas para colonizar a mucosa gástrica, sendo encontradas em maior densidade na região do antro ${ }^{30}$.

Observada no microscópio óptico e eletrônico, a $H$. pylori mede aproximadamente de $0,5 \mu \mathrm{m}$ a $0,1 \mu \mathrm{m}$ de largura e $3 \mu \mathrm{m}$ de comprimento, e quanto a sua morfologia, a bactéria apresenta-se encurvada ou espiralada, com sua superfície lisa e extremidades arredondadas e móveis. Seus flagelos são do tipo unipolares, indo de quatro a seis ${ }^{30}$.

A $H$. pylori consegue sobreviver nas bolsas periodontais na DP moderada ou avançada, uma vez que o hábitat apresenta-se favorável para esse tipo de microorganismo. De quinhentos indivíduos avaliados para a relação entre $H$.pylori e DP, em $54 \%$ dos casos havia coexistência das duas ${ }^{31}$.

Além disso, a $H$. pylori tem sido associada ao câncer de pâncreas. Em um estudo recente, um peptídeo homólogo ao dessa bactéria foi encontrado na maioria dos pacientes com pancreatite autoimune e em um pequeno grupo de pacientes com $\mathrm{ADP}^{22}$.

A relação desse microorganismo com a imunidade inata, por meio de lesão inflamatória, pode levar a carcinogênese, uma vez que peptídeos antigênicos de $H$. pylori translocados do intestino foram identificados em pacientes com pancreatite e com câncer de pâncreas ${ }^{11}$. 
No estudo realizado por Nilsson et al. ${ }^{32}$, o DNA da H. pylori foi identificado no pâncreas de $75 \%$ dos pacientes com câncer exócrino, $57 \%$ dos pacientes com câncer neuroendócrino, $38 \%$ dos pacientes com neoplasia endócrina múltipla e $60 \%$ dos pacientes com pancreatite crônica. Assim, mostrando-se uma associação de estatística significativa.

Para Nilsson et al. $^{32}$, citocinas próinflamatórias, EROS e outros mediadores inflamatórios associados à infecção por $H$. pylori podem induzir inflamação dos tecidos, aumentando os danos no DNA genômico e a proliferação celular, podendo levar à inativação dos genes supressores de tumores, o que facilita a transformação de células pancreáticas em malignas.

A colonização por $H$. pylori reduz 0 número de celular $D$ antrais no estômago, responsáveis por produzir somatostatina, o que resulta no aumento da produção de secretina. Foi demonstrado que a secretina possui um importante papel no crescimento pancreático e na síntese de DNA de células ductais do pâncreas ${ }^{33}$.

Pacientes com úlcera duodenal, devido a colonização por $H$. pylori, possuem a acidez aumentada. Essa acidez resulta em um aumento exacerbado no número de bactérias e na produção de nitrosaminas, as quais podem ser ativadas no epitélio do ducto pancreático e por meio da corrente sanguínea, transportadas até o pâncreas ${ }^{33,34}$.

As nitrosaminas são um fator indutor de câncer de pâncreas em animais e são também potencializadoras de câncer em humanos. Estima-se que as bactérias salivares e gastrointestinais sejam responsáveis por $45 \%$ a $75 \%$ de nitrosaminas, uma vez que estas convertem nitrato em nitrito e nitrosaminas. Além disso, a formação de nitrosaminas endógenas na cavidade oral de indivíduos com higiene oral precária é 8 vezes maior que em indivíduos com boa higiene oral ${ }^{35}$.

Há ainda, a hipótese de que a inflamação crônica causada pelos patógenos da periodontite sirva para a promoção de células já iniciadas, o que leva a um descontrole no crescimento celular. Outrossim, a falta de higiene oral leva a formação de nitrosaminas cancerígenas por bactérias redutoras de nitrato na cavidade oral ${ }^{36}$.

CONCLUSÃO

É possível que a doença periodontal seja um fator de risco para o desenvolvimento do cancro de pâncreas, visto os mecanismos relacionados em ambas as patologias. No entanto, ainda há mecanismos que se mantém sem respostas. Assim, a realização de mais pesquisas sobre essa correlação se faz necessária, para que haja esclarecimento sobre a ligação entre essas doenças. No caso de comprovação da correlação de ambas as doenças, deve-se haver certificação de prevenção da doença periodontal, para dessa maneira evitar que essa patologia evolua como um fator de risco para o desenvolvimento da neoplasia pancreática.

REFERÊNCIAS

1. Almeida VL, Leitão $A$, Reina LCB, Montanari CA, Donnici CL, Lopes MTP. Câncer e agentes antineoplásicos ciclo-celular específicos e ciclocelular não específicos que interagem com o DNA: uma introdução. Quím Nova. 2005;28(1): 118-29.

2. Gold DV, Modrak DE, Ying Z, Cardillo TM, Sharkey RB, Goldenberg DM. New MUC1 Serum Immunoassay Differentiates Pancreatic Cancer From Pancreatitis. J Clin oncol. 2006; 24(2):252-58.

3. Soldan M. Rastreamento do câncer de pâncreas. Rev Col Bras Cir. 2017;44(2):109-11.

4. Chang JS, Tsai CR, Chen LT, Shan YS. Investigating the association between periodontal disease and risk of pancreatic cancer. Pancreas. 2016;45(1):134-41.

5. Almeida RF, Pinho MM, Lima C, Faria I, Santos $\mathrm{P}$, Bordalo C. Associação entre doença periodontal e patologias sistémicas. Rev Port Clin Geral. 2006;22:379-90.

6. Alves C, Andion J, Brandão M, Menezes R. Mecanismos patogênicos da doença periodontal associada ao diabetes melito. Arq Bras Endocrinol Metab. 2007;51(7):1050-57.

7. Soares D, Andrade C, Pinto AR, Seabra M, Macho $V$. Doenças da gengiva e periodonto em crianças e adolescentes. Acta Pediatr Port. 2009;40(1):23-9.

8. Carvalho C, Cabral CT. Papel da Porphyromonas gingivalis na doença periodontal. Rev Port Estomatol Cir Maxilofac. 2007; 48(3):167-71.

9. Cordeiro AM, Oliveira IM, Rantería JM, Guimirães CA. Revisão sistemática: uma revisão narrativa. Rev Col Bras Cir. 2007;34(6):428-31.

10. Novak I. Purinergic receptors in the endocrine and exocrine pancreas. Purinergic Signal. 2008;4(3):237-53.

11. Velloso F, Leal-Lopes C, Correa RG, Sogayar MC. Importância do microbioma para o pâncreas. Manole; 2017.

12. Malhotra L, Ahn DH, Bloomston M (2015) The Pathogenesis, Diagnosis, and Management of Pancreatic Cancer. J Gastrointest Dig Syst 5:278. 
13. Ardengh JC, Coelho N, Osvaldt AB. Câncer do pâncreas em fase inicial: é possível identificá-lo através dos instrumentos científicos e propedêuticos disponíveis atualmente? Arq Gastroenterol. 2008;45(2):169-77.

14. Li D, Xie K, Wolff R, Abbruzzese JL. Pancreatic cancer. Lancet. 2004;363(9414):1049-57.

15. Hidalgo M. Pancreatic cancer. N Engl J Med. 2010;362(17):1605-17.

16. Takahashi $M$, Mutoh $M$, Ishigamori R, Fujii G, Imai $T$. Involvement of inflammatory factors in pancreatic carcinogenesis and preventive effects of anti-inflammatory agents. Semin Immunopathol. 2013;35(2):203-27.

17. Nazir MA. Prevalence of periodontal disease, its association with systemic diseases and prevention. Int $\mathrm{J}$ Health Sci (Qassim). 2017;11(2):72-80.

18. Kinane DF, Stathopoulou PG, Papapanou PN. Periodontal diseases. Nat Rev Dis Primers. 2017;3:17038.

19. Borgnakke WS. Does Treatment of Periodontal Disease Influence Systemic Disease? Dent Clin North Am. 2015;59(4):885-917.

20. Trombelli L, Farina R, Silva CO, Tatakis DN. Plaque-induced gingivitis: Case definition and diagnostic considerations. J Clin Periodontol. 2018;45 Suppl 20:S44-S67.

21. Vieira TR, Péret ACA, Péret Filho LA. Alterações periodontais associadas às doenças sistêmicas em crianças e adolescentes. Rev paul pediatr. 2010;28(2):237-43.

22. Farrell JJ, Zhang L, Zhou H, Chia D, Elashoff D, Akin $D$ et al. Variations of oral microbiota are associated with pancreatic diseases including pancreatic cancer. Gut. 2012;61(4):582-88.

23. Anil S, Varma SV, Preethanath RS, Anand PS, Aldosari FA. The emerging concepts on the impact of periodontitis on systemic health. In: Manakil J. Periodontal diseases - a clinician's guide; 2012. p.131-64.

24. Ahn J, Segers S, Hayes RB. Periodontal disease, Porphyromonas gingivalis serum antibody levels and orodigestive cancer mortality. Carcinogenesis. 2012;33(5):1055-58.

25. Michaud DS, Izard J, Wilhelm-Benartzi CS, You DH, Grote VA, Tjønneland A et al. Plasma antibodies to oral bacteria and risk of pancreatic cancer in a large European prospective cohort study. Gut. 2013;62(12):1764-70.

26. Zambirinis CP, Miller G. Signaling via MYD88 in the pancreatic tumor microenvironment: A double-edged sword. Oncoimmunology. 2013;2(1): e22567.

27. Michaud DS. Role of bacterial infections in pancreatic cancer. Carcinogenesis. 2013; 34(10):2193-97.

28. Zhou Y, Luo GH. Porphyromonas gingivalis and digestive system cancers. World J Clin Cases. 2019;7(7):819-29.
29. Wei MY, Shi S, Liang C, Meng QC, Hua J, Zhang $Y Y$ et al. The microbiota and microbiome in pancreatic cancer: more influential than expected. Mol Cancer. 2019;18(97):1-15.

30. Ladeira MSP, Salvadori DMF, Rodrigues MAM. Biopatologia do Helicobacter pylori. J Bras Patol Med Lab. 2003;39(4):335-42.

31. Nisha KJ, Nandakumar K, Shenoy KT, Janam P. Periodontal disease and Helicobacter pylori infection: a community-based study using serology and rapid urease test. J Investig Clin Dent. 2016;7(1):37-45.

32. Nilsson HO, Stenram U, Ihse I, Wadstrom T. Helicobacter species ribosomal DNA in the pancreas, stomach and duodenum of pancreatic cancer patients. World J Gastroenterol. 2006;12(19):3038-43.

33. Wang C, Li J. Pathogenic Microorganisms and Pancreatic Cancer. Gastrointest Tumors. 2015;2(1):41-7.

34. Risch HA. Pancreatic cancer: Helicobacter pylori colonization, N-nitrosamine exposures, and $A B O$ blood group. Mol Carcinog. 2012;51(1):109-18.

35. Stolzenberg-Solomon RZ, Dodd KW, Blaser MJ, Virtamo J, Taylor PR, Albanes D. Tooth loss, pancreatic cancer, and Helicobacter pylori. Am J Clin Nutr. 2003;78(1):176-81.

36. Meyer MS, Joshipura K, Giovannucci E, Michaud DS. A review of the relationship between tooth loss, periodontal disease, and cancer. Cancer Causes Control. 2008;19(9):895-907.

\section{CONFLITO DE INTERESSES}

Os autores declaram não haver conflitos de interesse

\section{AUTOR PARA CORRESPONDÊNCIA}

\author{
Aleson Pereira de Sousa \\ ORCID: https://orcid.org/0000-0002-3430-477X \\ Universidade Federal da Paraíba (UFPB), Brasil \\ E-mail: aleson_155@hotmail.com
}

